\title{
STUDI ANALISIS KETELITIAN GEOMETRIK CITRA SATELIT RESOLUSI TINGGI SEBAGAI PETA DASAR RENCANA DETAIL TATA RUANG PERINDUSTRIAN (STUDI KASUS : KAWASAN PT SIER SURABAYA)
}

\author{
Bangun Muljo Sukojo *1, Alfan Rozy Mahmudi² \\ ${ }^{123}$ Departemen Teknik Geomatika, FTSLK-ITS, Kampus ITS Sukolilo, Surabaya, 60111, Indonesia \\ e-mail: ${ }^{1}$ bangun_ms@geodesy.its.ac.id
}

\begin{abstract}
Abstrak
Kawasan PT SIER mempunyai lahan seluas 245 ha. Selain itu juga kawasan PT SIER ini terbagi menjadi 3 wilayah kecamatan yaitu Kecamatan Rungkut, Kecamatan Tenggilis Mejoyo, dan Kecamatan Gunung Anyar. Pada wilayah perindustrian dalam pemetaan wilayah tersebut digunakan peta detail yang mempunyai skala besar yaitu skala 1:5000 atau lebih. Dalam pembuatan peta tersebut dibutuhkan teknologi penginderaan jauh.

Teknologi penginderaan jauh sekarang sudah digunakan dan diaplikasikan dalam ilmu keBumian di Indonesia untuk informasi geospasialnya dalam skala lokal, regional, dan global. Pada penelitian yang dilakukan ini data yang digunakan untuk koreksi geometrik adalah citra satelit Worldview 2 tahun 2012 dengan resolusi spasial yaitu 0,46 meter dan Pleiades 1B tahun 2015 dengan resolusi spasial 0,5 meter. Selain itu juga data yang diperlukan pada penelitian ini adalah koordinat titik kontrol tanah atau yang disebut dengan Ground Control Point (GCP). Data koordinat titik kontrol diperoleh dari pengukuran di lapangan dengan menggunakan alat GPS Geodetik. Pengukuran yang dilakukan menggunakan metode statik selama kurang lebih 40 menit. Dalam melakukan koreksi geometrik pada penelitian ini menggunakan dua metode transformasi yaitu transformasi affine dan polynomial orde 2.

Hasil yang didapat dari penelitian ini menunjukkan bahwa desain jaring yang dibuat untuk pengukuran GPS mempunyai kekuatan jaring sebesar 0.116274 . Kekuatan jaring tersebut sudah masuk toleransi yaitu $\leq 1$. Untuk hasil koreksi geometrik pada citra Worldview 2 dan citra Pleiades 1B menggunakan 2 metode. Pada metode affine nilai Root Mean Square Error (RMSE) untuk Worldview 2 sebesar 0.306359 sedangkan RMSE untuk Pleiades 1B sebesar 0.319769. Pada metode polynomial orde 2, RMSE untuk Worldview 2 sebesar 0.163263 sedangkan RMSE untuk Pleiades 1B sebesar 0.218205. Dilihat dari RMSE yang didapat kedua citra tersebut dapat dijadikan dasar pembuatan peta dengan skala 1:5000.
\end{abstract}

Kata Kunci - Pleiades 1B, Worldview 2, RMSE, Koreksi Geometrik.

\begin{abstract}
PT SIER region has an area of 245 ha. In addition, PT SIER region is divided into three sub-districts, namely Rungkut District, Tenggilis Mejoyo District, and Gunung Anyar Disrict. In the industrial area in the mapping of the region that have used a detailed map of a large scale is a scale of 1: 5000 or more. The remote sensing technology is needed for making the maps.

Remote sensing technology is now used and applied in geoscience Indonesia for geospatial information on a local, regional, and globalThis research conducted data used for geometric correction is WorldView 2 satellite imagery with a spatial resolution of 2012 which is 0.46 meters and the Pleiades $1 B$ in 2015 with a spatial resolution of 0.5 meters. In addition, the necessary data in this study are the coordinates of ground control points or so-called the Ground Control Point (GCP). The GCP coordinate data obtained from measurements in the field using geodetic GPS device. Measurements were performed using the static method for approximately 40 minutes. In doing geometric correction in this study using two methods, namely the transformation affine transformation and polynomial order 2

The results of this study indicate that the design of nets made to the GPS measurements have strength webs of 0.116274 . The net strength has entered tolerance is $\leq 1$. For the geometric correction to both images using two methods. In the method of affine value Root Mean Square Error (RMSE) for WorldView 2 is 0.306359 while the RMSE for the Pleiades $1 B$ amounted to 0.319769 . In order polynomial method 2, RMSE for WorldView 2 is 0.163263 while the RMSE for the Pleiades $1 B$ amounted to 0.218205 . The RMSE obtained both images can be used as a basis for making a map with a scale of 1: 5000
\end{abstract}

Keywords-Pleiades 1B, Worldview 2, RMSE, Geometric Correction. 


\section{PENDAHULUAN}

Surabaya Industrial Estate Rungkut (SIER) Surabaya. Kawasan PT SIER ini mempunyai lahan seluas 245 ha (SIER, 2016). Selain itu juga kawasan PT SIER ini terbagi menjadi 3 wilayah kecamatan yaitu Kecamatan Rungkut, Kecamatan Tenggilis

Mejoyo, dan Kecamatan Gunung Anyar. Pada wilayah perindustrian dalam pemetaan wilayah tersebut digunakan peta detail yang mempunyai skala besar yaitu skala 1:5000 atau lebih. Dalam pembuatan peta tersebut dibutuhkan teknologi penginderaan jauh.

Dewasa ini teknologi dan sains sangat pesat dalam perkembangannya. Terutama pada teknologi penginderaan jauh seperti satelit, satelit radar, radar, dan LiDAR telah pesat dalam penggunaanya. Teknologi penginderaan jauh sekarang sudah digunakan dan diaplikasikan dalam ilmu keBumian di Indonesia untuk informasi geospasialnya dalam skala lokal, regional, dan global. Perkembangan teknologi penginderaan jauh juga dapat dilihat dengan munculnya satelit-satelit yang mempunyai resolusi spasial tinggi.

Terdapat banyak satelit yang mempunyai resolusi tinggi salah satu contohnya adalah satelit Worldview dan satelit Pleiades. Data dari satelit Worldview dan Pleiades mempunyai resolusi tinggi yaitu 0.46 meter dan 0.5 meter yang merupakan citra pada umumnya masih terdapat kesalahan geometrik (LAPAN, 2015). Kesalahan geometrik merupakan kesalahan yang diakibatkan oleh jarak orbit atau lintasan terhadap objek (hingga sudut pandang kecil dan pengaruh kecepatan wahana (Hartati, 2009). Kesalahan geometrik diakibatkan oleh dua kesalahan yaitu kesalahan sistematik dan non sistematik. Untuk menghlangkan kesalahan tersebut maka perlu dilakukan koreksi geeometrik.

Koreksi geometrik merupakan kegiatan untuk memperbaiki koordinat yang ada pada citra agar sesuai dengan koordinat geografis. Pada umunya koreksi geometrik citra dilakukan dengan membutuhkan koordinat 2 dimensi $(x, y)$ atau koordinat Ground Control Point (GCP) sebagai data inputnya. Koordinat GCP ini digunakan untuk memberi atau memperbaiki citra dimana akan terlihat titik akurasi GCP tersebut dengan melihat nilai Root Mean Square Error (RMSE).

Pada penelitian ini akan dilakukan analisa ketelitian geometrik pada citra satelit Worldview dan Pleiades yang digunakan untuk pembuatan peta dasar detail tata ruang perindustrian. Penelitian ini diharapkan untuk diketahui ketelitian geometrik pada citra Worldview dan plaiades yang memenuhi toleransi dalam pembuatan peta dasar detail tata ruang.

\section{METODOLOGI PENELITIAN}

Lokasi penelitian pada Tugas Akhir ini dilakukan pada kawasan perindustrian PT SIER yang terbagi menjadi 3 kecamatan yaitu Kecamatan Tenggilis Mejoyo, Kecamatan Rungkut, dan Kecamatan Gunung Anyar yang terletak pada koordinat 7¹8'23.5"LS $112^{\circ} 45^{\prime} 39.8^{\prime \prime}$ BT sampai dengan 7²0'31.2"LS 11249'33.3"BT :

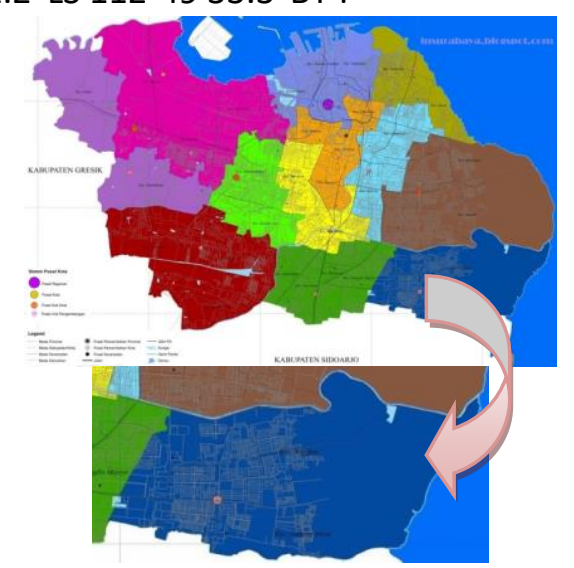

Gambar 1. Lokasi Penelitian (Sumber : Insurabaya)

\section{Tahap Pengolahan Data}

Pada tahap pertama pengolahan data yang dilakukan adalah melakukan proses pansharpening. Pada proses ini dilakukan agar mendapat hasil citra yang baik dan jelas dengan cara menggabungkan dua band yaitu multispektral dan pankromatik. Citra yang dilakukakn proses pansharpening adalah citra Pleidaes $1 \mathrm{~B}$, yang di mana hasil pansharpening dari citra ini mempunyai resolusi spasial tinggi sebesar 0,5 meter.

Langkah selanjutnya adalah penempatan titik GCP. Titik GCP ini digunakan untuk proses rektifikasi pada kedua citra Pleiades 1B dan Worldview 2. Setelah citra sudah didapatkan resolusi spasial yang tinggi dari hasil pansharpening maka dapat dengan mudah untuk melakukan interpretasi pada citra dan memudahkan untuk meletakkan titik GCP pada objek yang mudah teridentifikasi di citra maupun di lapangan. 
Titik-titik GCP tersebut akan di hubungkan dengan baseline antar titik. Dari baseline tersebut akan didapat desain jaring dari tiap titik-titik tersebut. Desain jaring tersebut dapat dihitung nilai kekuatan jaringnya. Pada penelitian ini menghitung kekuatan jaring (SOF) dengan menggunakan metode perataan bersyarat. Terdapat juga nilai toleransi untuk nilai kekuatan jaring yaitu < 1 . Jika nilai tersebut belum memenuhi maka perlu dilakukan lagi peletakan titik GCP sampai nilai tersebut memenuhi dan dilakukan pengukuran.

Setelah mendapat koordinat tiap titik-titik GCP tersebut maka dilakukan proses rektifikasi pada kedua citra tersebut yaitu Worldview 2 dan Pleiades 1B. Proses rektifikasi ini dilakukan dengan dua metode transformasi affine dan polynomial orde 2. Hasil rektifikasi ini juga mempunyai toleransi yaitu $\leq 1$

Langkah selanjutnya merupakan uji ketelitian geometrik pada citra Worldview 2 dan Pleiades 1B. uji ketelitian dilakukan dengan cara memberikan titik ICP pada area dalam desain jaring yang telah dibuat. Untuk penentuan jumlah titik ICP ini menggunakan buku panduan dari BIG dimana jumlah titik ICP ditentukan dari luas area yang di ukur. Pada penelitian ini menggunakan 12 titik ICP yang sudah sesuai dengan buku panduan BIG di mana denga luas area $\leq 250 \mathrm{~km}^{2}$ terdapat minimal 12 titik ICP (Badan Informasi Geosasial, 2016).

Analisa yang dilakukan yaitu dengan menggunakan perka BIG nomor 15 tahun 2014. Pada perka tersebut hasil RMSE dari uji ketelitian menggunakan ketelitian geometrik atau CE90 sebesar 1,5175 X RMSE.

\section{HASIL DAN PEMBAHASAN \\ Hasil Pansharpening Citra}

Pansharpening merupakan proses penajaman citra dari band multispektral digabungkan dengan citra band pankromatik. Tujuan dilakukannya pansharpening untuk memudahkan proses interpretasi citra, penentuan titik kontrol dan tampilan citra yang memiliki visual yang baik serta memiliki resolusi yang tinggi. Pansharpening ini dilakukan untuk meningkatkan resolusi spasial yang ada pada citra Pleiades 1B dengan cara mengubah resolusi spasial multispektral dengan resolusi spasial pankromatik. Berikut ini adalah hasil citra satelit pleiades 1B sebelum dan sesudah dilakukannya pan-sharpen pada citra satelit Pleiades 1B :

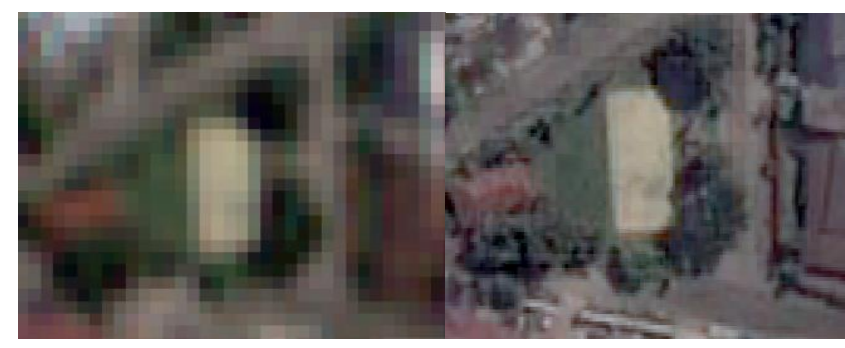

Gambar 2. Penampakkan citra sebelum proses pansharpening (Kiri) dan setelah (Kanan)

Dapat dilihat dari gambar diatas bahwa setelah dilakukannya pan-sharpening pada citra Pleiades 1B, citra satelit menjadi mudah untuk di interpretasi. Ini dikarenakan citra telah dirubah dari resolusi spasial rendah pada multispektral sebesar 2 meter menjadi resolusi spasial tinggi pada pankromatik sebesar 0,5 meter

\section{Penentuan dan Sebaran Titik Kontrol}

Pada Pemilihan lokasi titik kontrol tanah atau yang disebut dengan Ground Control Point (GCP) sebaiknya diletakkan di daerah yang mudah untuk dikenali pada citra satelit. Daerah tersebut seperti sungai, ujung jalan, pertigaan jalan, perempatan jalan, jembatan dan penampakan-penampakan alam yang tidak mudah/cepat berubah. Pemilihan lokasi titik kontrol ini sangat mempengaruhi hasil Root Mean Square Error (RMSE) dari proses koreksi geometrik pada citra yang akan dilakukan.

Titik GCP pada penelitian ini tersebar pada 3 kecamatan. Untuk Kecamatan Tenggilis Mejoyo terdapat 4 titik GCP, Kecamatan Rungkut terdapat 3 titik GCP, dan sedangkan Kecamatan Gunung Anyar terdapat 2 titik GCP.

Adapun sebaran titik kontrol yang juga telah dilakukan pengukuran yaitu:

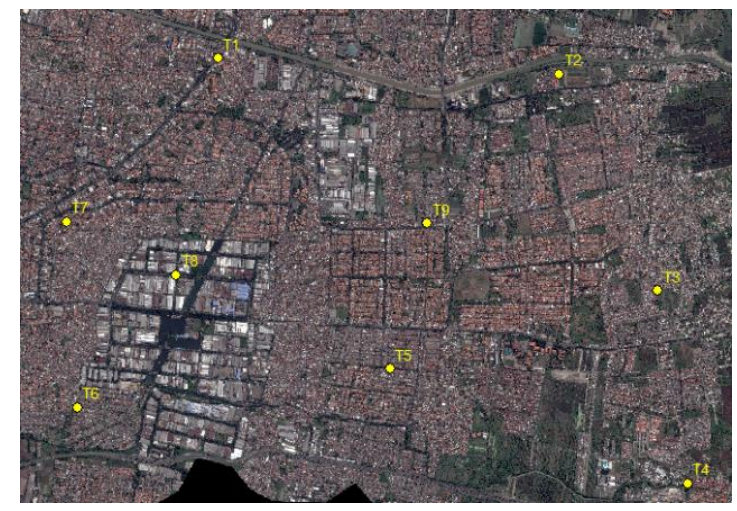


Gambar 3. Sebaran Titik Kontrol (GCP)

\section{Kekuatan Jaring}

Pada penelitian ini dilakukan pengukuran titik kontrol tanah (GCP) dengan menggunakan GPS geodetik untuk melakukan koreksi geometrik. Sebelum melakukan pengukuran untuk mendapatkan koordinat titik kontrol tanah tersebut maka dilakukan pembuatan desain jaring pengukuran titik kontrol. Pada penelitian ini menggunakan 9 titik GCP yang tersebar pada kawasan perindustrian. Kemudian tiap titik GCP tersebut dihubungkan oleh baseline, yang disesuaikan dengan rencana pengukuran dilapangan. Dapat dilihat hasil desain jaring yang sudah dibuat pada penelitian ini Untuk melihat kekuatan dari jaringan yang dibentuk, maka dilakukan penghitungan kekuatan jaring atau Strength of Figure.

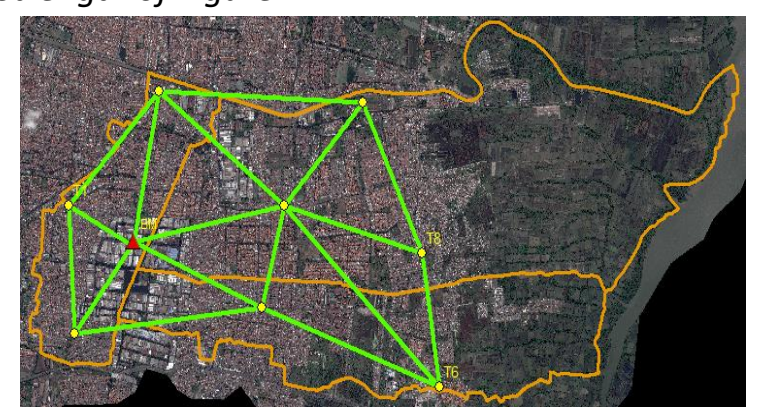

Gambar 4. Desain Jaring

Perhitungan nilai kekuatan jaring ini menggunakan metode perataan bersyarat. Berikut ini adalah hasil perhitungan kekuatan jaring dari desain jaring yang suda dibuat dengan menggunakan metode perataan bersyarat (Sukojo, 2006) :

- Jumlah titik (S)

- Jumlah baseline (N)

- $\mathrm{S}^{\prime}$

- $\mathrm{N}^{\prime}$

- $C=C_{a}+C_{s}=\left(N^{\prime}-S^{\prime}+1\right)+(N-2 S+3)=3$

- $D=2 x\left(N^{\prime}-1\right)+\left(N-N^{\prime}\right)$ $=22$

- $\left\lfloor\sum\left(\delta_{A}^{2}+\delta_{A} \cdot \delta_{B}+\delta_{B}^{2}\right)\right]$ $=0,214$

- $R=\frac{(D-C)}{C}\left[\sum\left(\delta_{A}^{2}+\delta_{A} \cdot \delta_{B}+\delta_{B}^{2}\right)\right]$ $=0,184$

\section{A. Hasil Koreksi Geometrik dan Uji Ketelitian Geometrik}

Hasil RMSE didapat dari tranformasi koordinat yang ada di citra ke dalam koordinat titik kontrol tanah sebagai acuan dan akan menghaslkan residu pada setiap titik kontrol. Residu merupakan hasil dari selisih antara koordinat titik kontrol hasil pengukuran GPS yang dianggap benar dengan koordinat hasil transformasi pada citra Worldview 2 dan Pleiades 1B. Berikut ini hasil RMSE yang ada pada citra Worldview 2 dan Pleiades 1B dengan menggunakan 2 metode yaitu affine dan polynomial orde 2. Adapun secara rinci ditunjukkan pada tabel berikut:

Tabel 1. Hasil Perhitungan RMSE Worldview 2

\begin{tabular}{|c|c|c|c|}
\hline \multirow{2}{*}{ No. } & \multirow{2}{*}{$\begin{array}{c}\text { Nama } \\
\text { Titik }\end{array}$} & \multicolumn{2}{|c|}{ RMS Tiap Titik } \\
\cline { 3 - 4 } & & Affine & $\begin{array}{c}\text { Polynomial } \\
\text { orde 2 }\end{array}$ \\
\hline 1. & T1 & 0,309591 & 0,369793 \\
\hline 2. & T2 & 0,372051 & 0,066578 \\
\hline 3. & T3 & 0,227591 & 0,040638 \\
\hline 4. & T4 & 0,345736 & 0,086377 \\
\hline 5. & T5 & 0,365777 & 0,033921 \\
\hline 6. & T6 & 0,239593 & 0,201927 \\
\hline 7. & T7 & 0,319360 & 0,201316 \\
\hline 8. & T8 & 0,270871 & 0,203045 \\
\hline 9 & T9 & 0,270850 & 0,078110 \\
\hline \multicolumn{2}{|r|}{ Total RMSE } & 0,306359 & 0,163263 \\
\hline
\end{tabular}

Tabel 2. Hasil Perhitungan RMSE Error Pleiades 1B

\begin{tabular}{|c|c|c|c|}
\hline \multirow{2}{*}{ No. } & Nama & \multicolumn{2}{|c|}{ RMS Tiap Titik } \\
\cline { 3 - 4 } & Titik & Affine & $\begin{array}{c}\text { Polynomial } \\
\text { orde 2 }\end{array}$ \\
\hline 1. & T1 & 0,284587 & 0,088726 \\
\hline 2. & T2 & 0,410164 & 0,154270 \\
\hline 3. & T3 & 0,219868 & 0,033286 \\
\hline 4. & T4 & 0,260116 & 0,007127 \\
\hline 5. & T5 & 0,329610 & 0,278653 \\
\hline 6. & T6 & 0,308986 & 0,168951 \\
\hline 7. & T7 & 0,312130 & 0,180229 \\
\hline 8. & T8 & 0,277568 & 0,318404 \\
\hline 9 & T9 & 0,420074 & 0,394505 \\
\hline \multicolumn{2}{|r|}{ Total RMSE } & 0,319769 & 0,218205 \\
\hline
\end{tabular}

\section{Hasil Uji Ketelitian Geometrik}

Ketelitian geometrik ini dilakukan dengan menggunakan koordinat ICP hasil pengukuran dilapangan. Koordinat ICP didapatkan dari 
pengukuran lapangan selama 10-20 menit. Jumlah titik ICP yang digunakan berjumlah 12 titik ICP. Berikut ini persebaran titik ICP yang digunakan :

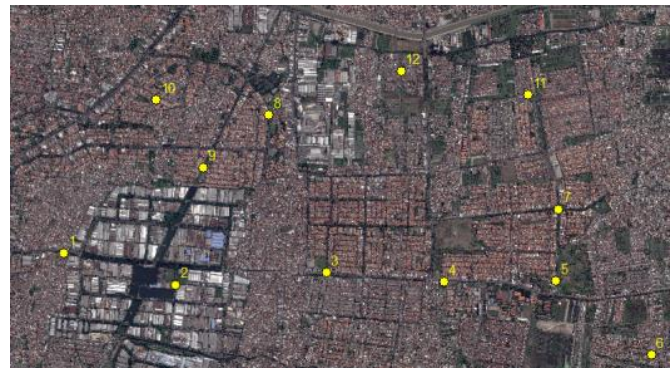

Gambar 5. Sebaran Titik ICP

Tabel 3. Hasil RMSE Uji ICP pada Pleiades 1B

\begin{tabular}{|c|c|c|c|c|}
\hline \multirow{2}{*}{ No. } & \multirow{2}{*}{ Nama Titik } & \multicolumn{3}{|c|}{ Pleiades 1B } \\
\cline { 3 - 5 } & & $\begin{array}{c}\text { Residual } \\
\mathbf{X}\end{array}$ & Residual Y & Residual Titik \\
\hline 1 & ICP1 & 0,483 & $-0,782$ & 0,835950358 \\
\hline 2 & ICP2 & 0,436 & 0,713 & 0,354492595 \\
\hline 3 & ICP3 & 0,5 & $-0,189$ & 0,534528765 \\
\hline 4 & ICP4 & 0,664 & 0,28 & 0,384832431 \\
\hline 5 & ICP5 & 0,506 & 0,184 & 0,538416195 \\
\hline 6 & ICP6 & 0,525 & $-0,112$ & 0,153521987 \\
\hline & & \multicolumn{4}{|c|}{ Pleiades 1B } \\
\cline { 3 - 5 } No. & Nama Titik & $\begin{array}{c}\text { Residual } \\
\mathbf{X}\end{array}$ & Residual Y & Residual Titik \\
\hline 8 & ICP8 & 0,327 & $-0,369$ & 0,493041581 \\
\hline 9 & ICP9 & 0,352 & 0,542 & 0,646272388 \\
\hline 10 & ICP10 & 0,516 & $-0,843$ & 0,890452132 \\
\hline 11 & ICP11 & 0,606 & $-0,293$ & 0,565053096 \\
\hline 12 & ICP12 & 0,463 & $-0,156$ & 0,305785873 \\
\hline \multicolumn{5}{|c}{ Total RMSE } \\
\hline \multicolumn{5}{|c}{} \\
\hline
\end{tabular}

Tabel 4. Hasil RMSE Uji ICP pada Worldview 2

\begin{tabular}{|c|c|c|c|c|}
\hline \multirow{2}{*}{ No. } & \multirow{2}{*}{ Nama Titik } & \multicolumn{3}{|c|}{ Worldview 2 } \\
\cline { 3 - 5 } & & $\begin{array}{c}\text { Residual } \\
\mathbf{X}(\mathbf{m})\end{array}$ & $\begin{array}{c}\text { Residual } \\
\mathbf{Y}(\mathbf{m})\end{array}$ & Residual Titik \\
\hline 1 & ICP1 & 0,265 & $-0,329$ & 0,422452364 \\
\hline 2 & ICP2 & 0,24 & 0,168 & 0,292957335 \\
\hline 3 & ICP3 & 0,427 & $-0,291$ & 0,516730104 \\
\hline 4 & ICP4 & 0,536 & 0,346 & 0,637974921 \\
\hline 5 & ICP5 & 0,549 & $-0,32$ & 0,635453382 \\
\hline 6 & ICP6 & 0,377 & $-0,416$ & 0,561413396 \\
\hline 7 & ICP7 & 0,292 & 0,18 & 0,343021865 \\
\hline 8 & ICP8 & 0,436 & $-0,104$ & 0,448232083 \\
\hline 9 & ICP9 & 0,409 & 0,193 & 0,452249931 \\
\hline 10 & ICP10 & 0,342 & $-0,361$ & 0,497277588 \\
\hline 11 & ICP11 & 0,451 & $-0,475$ & 0,655000764 \\
\hline 12 & ICP12 & 0,237 & $-0,334$ & 0,409542428 \\
\hline \multicolumn{5}{|c|}{ Total RMSE } \\
\hline
\end{tabular}

\section{B. Analisis Ketelitian Geometrik}

Hasil RMSE ICP selanjutnya dibandingkan dengan ketelitian peta dasar. Peta dasar yang dibuat merupakan peta dasar detail tata ruang perindusrian. Syarat pembuatan peta ini harus mempunyai spesifikasi skala besar yaitu pada peta skala 1:5000 atau skala yang lebih besar lagi. Berikut ini terdapat ketentuan ketelitian peta dasar dari Perka BIG Nomor 15 tahun 2014. Nilai ketelitian posisi peta dasar pada Tabel adalah nilai CE9O (Circular Error 90\%) merupakan ketelitian horizontal, yang berarti bahwa kesalahan posisi peta dasar tidak melebihi nilai ketelitian tersebut dengan tingkat kepercayaan 90\%, dengan ketentuan CE90 : 1,5175 x RMS Error Total, selanjutnya dapat dikatakan ketelitian tersebut memenuhi skala peta tertentu (Peraturan Kepala BIG nomor 15, 2014).

Tabel 5. Ketelitian Geometrik Peta

\begin{tabular}{|c|c|c|}
\hline No. & Skala Peta & Ketelitian Peta Dasar (horizontal) \\
\hline 1 & $1: 25000$ & $5-12,5$ meter \\
\hline 2 & $1: 10000$ & $2-5$ meter \\
\hline 3 & $1: 5000$ & $1-2,5$ meter \\
\hline No. & Skala Peta & Ketelitian Peta Dasar (horizontal) \\
\hline 4 & $1: 2500$ & $0,5-1,5$ meter \\
\hline 5 & $1: 1000$ & $0,2-0,5$ meter \\
\hline
\end{tabular}

Berdasarkan hasil perhitungan RMSE yang telah didapatkan pada masing-masing citra maka dapat dihitung ketelitian geometrik horizontalnya yaitu:

Tabel 6. Hasil Ketelitian Geometrik Citra

\begin{tabular}{|c|c|c|}
\hline No. & Nama Citra & Hasil RMSE X 1,5175 \\
\hline 1 & Worldview 2 & 0,761834373 \\
\hline 2 & Pleiades 1B & 0,826797775 \\
\hline
\end{tabular}

Dari hasil diatas data dilihat bahwa setelah melakukan perhitungan ketelitian untuk peta dasar citra Worldview 2 dan Pleiades 1B dapat digunakan pada skala 1:5000.

\section{KESIMPULAN}

Kesimpulan yang dapat diambil dari penelitian ini adalah sebagai berikut:

1.Pada metode affine diperoleh nilai RMSE sebesar 0,306359 pada citra Worldview 2 dan 0,319769 pada citra Pleiades 1B. Pada metode polynomial orde 2 diperoleh nilai RMS untuk citra Worldview 2 dan Pleiades 1B yaitu sebesar 0,163263 dan 0,218205 . Nilai RMS terkecil di titik Citra Worldview 2 dan pleiades 1B dengan menggunakan metode affine yaitu pada titik 3 dengan nilai sebesar 0,227591 dan 0,219868. 
sedangkan nilai RMS terbesar ada pada titik 5 untuk citra Worldview 2 yaitu 0,365777 dan untuk citra Pleiades 1B pada titik 9 sebesar 0,420074 . Pada metode polynomial orde-2 nilai RMS per titik terkecil pada titik 4 sebesar 0,007127 untuk citra Pleiades 1B dan pada titik 5 sebesar 0,033921 untuk citra Worldview 2. Sedangkan nilai RMS per titik terbesar sebesar 0,394505 pada citra Pleiades 1B dan 0,203045 pada citra Worldview 2. Dari hasil peneletian koreksi geometrik ini menghasilkan RMSE pada kedua citra masuk toleransi yaitu dibawah dari nilai 1.

2.Kelayakan citra untuk Worldview 2 dan Pleiades $1 \mathrm{~B}$ untuk pembuatan peta dasar detail tata ruang dapat dilihat dari hasil RMSE ICP dikalikan dengan 1,5175(CE90). Citra Worldview 2 dan Pleiades 1B dapat digunakan pada peta skala 1:5000 kelas 1 dimana sesuai dengan perka BIG No. 15 Tahun 2014 yang mempunyai standar nilai ketelitian sebesar 1 meter. Peta 1:5000 merupakan standar minimal untuk peta dasar detail tata ruang perindustrian.

\section{UCAPAN TERIMA KASIH}

Kami sampaikan terima kasih kepada kepada Departemen Geomatika ITS yang telah memberikan dukungan administrasi dan pendanaan sehingga penelitian ini dapat berjalan dengan baik dan lancar.

\section{DAFTAR PUSTAKA}

LAPAN. (2015). Pusat Pemanfaatan Teknologi Dirgantara. Retrieved from Spesifikasi Citra Satelit Pleiades: pusfatekgan.lapan.go.id

LAPAN. (2015). Pusat Pemnafaatan Teknologi Dirgantara. Retrieved from Spesifikasi Citra Satelit Worldview: pusfatekgan.lapan.go.id

Peraturan Kepala BIG nomor 15. (2014). Tentang Pedoman Teknik Ketelitian Peta Dasar. Bogor: Badan Informasi Geospasial.

PT SIER. (2016). Tentang SIER. 2016. http://sierpier.com/?page_id=126\&lang=id

Sukojo, B. M. (2006). "Modul Ajar Hitung Kerangka Geodesi." Surabaya: Teknik Geomatika Institut Teknologi Sepuluh Nopember

Hartati, Sri. (2009). Aplikasi Penginderaan Jauh untuk Ilmu KeBumian. Bandung: Institut Teknologi Bandung 